\title{
Prevalence of rilpivirine resistance in people starting antiretroviral treatment in Argentina
}

Emiliano Bissio, Maria G Barbás, Silvia Kademián, Maria B Bouzas, Horacio Salomón, Analia Cudolá, Silvina Fernández Giuliano, Carlos Falistocco

Antiviral Therapy 2017; 10.3851/IMP3147

Submission date Acceptance date Publication date 10th February 2017 20th February 2017 24th February 2017

This provisional PDF matches the article and figures as they appeared upon acceptance. Copyedited and fully formatted PDF and full text (HTML) versions will be made available soon.

For information about publishing your article in Antiviral Therapy go to http://www.intmedpress.com/index.cfm?pid=12 


\title{
Short communication
}

\section{Prevalence of rilpivirine resistance in people starting antiretroviral treatment in Argentina}

\author{
Emiliano Bissio ${ }^{*}$, Maria G Barbás², Silvia Kademián², Maria B Bouzas ${ }^{3}$, Horacio \\ Salomón ${ }^{4}$, Analia Cudolá2, Silvina Fernández Giuliano ${ }^{3}$, Carlos Falistocco ${ }^{5}$ \\ ${ }^{1}$ Fundación Centro de Estudios Infectológicos (FUNCEI), Buenos Aires, Argentina \\ ${ }^{2}$ Laboratorio Central de Córdoba, Córdoba, Argentina \\ 3unidad de Virología, División Análisis Clínicos, Hospital de Infecciosas F. J. Muñiz, Buenos Aires, \\ Argentina
}

${ }^{4}$ Instituto de Investigaciones Biomédicas en Retrovirus y SIDA (INBIRS), Universidad de Buenos Aires, Buenos Aires, Argentina

${ }^{5}$ Dirección de Sida, Ministerio de Salud de la Nación, Buenos Aires, Argentina

*Corresponding author e-mail: ebissio@gmail.com

\section{ABSTRACT}

Background: Rilpivirine-based regimens are now preferred or alternative firstline regimens according to many HIV treatment guidelines. Recently, a surveillance study conducted in our country determined that prevalence of pretreatment resistance to first-generation NNRTIs was $10 \%$. The aim of this study was to analyze the prevalence of resistance mutations to newer generation NNRTIs in the population starting ART in Argentina.

Methods: We analyzed the prevalence of resistance mutations to rilpivirine and etravirine (according to the IAS list), obtained through a nationally representative pretreatment HIV-drug resistance (PDR) surveillance study performed in Argentina in 2014-2015. Briefly, 25 ART-dispensing sites throughout the country were randomly chosen to enroll 330 adults starting ART. Samples were processed with Trugene (Siemens) ${ }^{\circledR}$, and analyzed using the Stanford algorithm.

Results: All 270 samples corresponding to participants with no prior exposure to antiretroviral drugs were included in this analysis. Median (IQR) age was 35 years (28-43); $66.7 \%$ were male; median(IQR) CD4 count was $284 / \mathrm{mm} 3(112-$ $489)$. The prevalence of resistance to any antiretroviral was $16 \%( \pm 5 \%)$, and prevalence of NNRTI RAMs was $13 \%( \pm 4 \%)$. The prevalence of resistance to rilpivirine was $8 \%( \pm 3 \%)$. Prevalence of resistance to etravirine was $4 \%( \pm 3 \%)$. The most frequent mutations conferring resistance to rilpivirine were: E138A $(n=6)$ and G190A ( $n=4)$.

Conclusions: This PDR surveillance study showed concerning levels of HIVDR in Argentina, not only for first-generation NNRTIs but also to rilpivirine. In our setting, performing resistance testing would be necessary before prescription of ART even if a second-generation NNRTI based regimen were used as firstline therapy. 
Publication: Antiviral Therapy; Type: Short communication

DOI: $10.3851 / \mathrm{IMP} 3147$

Running title: Rilpivirine resistance in ART initiators

\section{INTRODUCTION}

Rilpivirine, a newer generation NNRTI, is currently recommended as part of the Preferred or Alternative regimens to initiate antiretroviral treatment (ART) in patients with HIV infection and a viral load less than 100000 copies/mL. This NNRTI is a potent diarylpyrimidine (DAPY) analog that shows potent activity against wild-type HIV-1 group $M$ and group $O$ isolates. It is better tolerated than efavirenz, and has a different resistance profile. However, rilpivirine has also a low genetic barrier for generation of resistance, and cross-resistance with older NNRTIs is frequent, especially with nevirapine. In low- and middle-income countries (LMIC), efavirenz-based regimens continue to be the recommended choice for ART initiation, but in some countries or regions, an alarming prevalence of transmitted or pre-treatment resistance to first-generation NNRTIs has been described [1-3]. Due to its relative low cost and better tolerance, rilpivirine might become an alternative for ART initiation also in some LMIC, and it is being evaluated as second-line agent for patients who experienced treatment failure from nevirapine- or efavirenz-based regimens in other [4]. In Argentina, rilpivirine is not recommended yet for starting antiretroviral treatment by the Ministry of Health Guidelines [5], but it is now a recommended initial option according to the latest version of the Guidelines from the Argentine Society of Infectious Diseases (SADI) [6]. Both documents recommend performing resistance testing before treatment initiation; however, the majority of patients in this country still initiate ART without being tested for HIV resistance.

To our knowledge, there are few reports about the prevalence of transmitted or pretreatment resistance to rilpivirine in LMIC; and the reported global data state that prevalence of pretreatment resistance to rilpivirine is low [7]. However, resistance seems to be higher in some regions, as in Europe [8-11] and in South America/Caribbean [7]. During 2014/2015, Argentina performed a survey to determine the prevalence of pre-treatment drug resistance in people starting ART throughout the country (with or without prior exposure to antiretroviral drugs) [2]. Mutations conferring resistance to second-generation NNRTIs were not considered in the original analysis since neither rilpivirine nor etravirine were recommended as first-line options at that time.

The aim of this study was to analyze the prevalence of resistance to rilpivirine in people starting ART with no prior exposure in Argentina. A secondary objective was to determine the prevalence of pre-treatment resistance to etravirine in the mentioned population.

\section{METHODS}

This report is a secondary analysis from a Pretreatment HIV Drug Resistance Survey performed in Argentina during 2014/2015. The survey details have been described elsewhere [2]. Briefly, this was a study performed according to WHO HIVDR Surveillance Strategy [12], in which we sampled the HIV clinics throughout the country to obtain a nationally representative sample that would allow generation of a point prevalence estimate of resistance with a narrow confidence interval. All persons starting 
ART in the selected sites during the study period were eligible if they were $\geq 18$ years old, were prescribed a first-line antiretroviral regimen, accepted to participate and signed informed consent. Exclusion criteria were: infection by HIV-2 and being transferred from other clinic but already on antiretroviral treatment. After gathering demographic and clinical data, a $10 \mathrm{~mL}$ blood specimen was collected for performance of a resistance testing.

The Stanford HIVdb algorithm [13] was used to determine HIVDR. Sequences classified as "susceptible" and "potential low-level resistance" were considered as having no HIVDR. For the present analysis, we used the last version of the IAS list in order to describe the mutations [14]; incorporating the mutations associated with resistance to rilpivirine and etravirine (that were not considered in the original analysis).

\section{Laboratory methods}

Plasma was the specimen type used, handled according to WHO recommendations on plasma collection, processing and storage for HIVDR testing [15]. All specimens collected were processed by any of the 3 national reference laboratories of Argentina. The samples were sequenced using the Trugene ${ }^{\circledR}$ HIV-1 Genotyping Kit (Siemens Healthcare Diagnostics, Tarrytown, NY, USA), following the manufacturer's instructions [16]. The sequences were analyzed for resistance mutations using the Stanford University "Genotypic Resistance Interpretation Algorithm HIVdb" program (Version 7.0 last updated 02/27/2014) [13]. For HIV-1 subtype assignment the following tools were used: REGA HIV-1 Subtyping Tool Version 3.0 (http://dbpartners.stanford.edu:8080/RegaSubtyping/stanfordhiv/typingtool/) and NCBI Genotyping tool (https://www.ncbi.nlm.nih.gov/projects/genotyping/formpage.cgi)

\section{Statistical Analysis}

The sample size was calculated aiming to obtain an HIVDR point prevalence number with a confidence interval of maximum $\pm 5 \%$ for all individuals starting ART without previous antiretroviral exposure. The following assumptions were made for sample size calculation: Clinics to be sampled: 30; estimated prevalence of pre-treatment HIVDR: 10\%; proportion of genotyping failure: 20\%; proportion of ART initiators with prior exposure to ARV: $25 \%$; and proportion of individuals starting NNRTI based regimens in Argentina: $70 \%$. We used the $\chi 2$ or Fisher's exact test to compare the prevalence of drug resistance across groups.

\section{Ethical Considerations}

All participants provided written informed consent at enrolment. The study protocol was reviewed and approved by a central Ethics Committee (CIEIS del Niño y del Adulto, approval date: July 28th 2014); and by the Institutions' local Ethics Committees if it was required. 


\section{RESULTS}

Participants were recruited from 25 survey sites (accounting for 30), since the 2 largest clinics in the country were randomly selected more than once. We enrolled 330 participants from whom we collected plasma specimens for resistance testing. For the present analysis, only those without prior antiretroviral exposure were considered ( $n=270)$. Median (IQR) age was 35 years $(28-43) ; 66.7 \%$ were male, 0.7\% were transgender; median (IQR) CD4+ cell count was 284/mm3 (112-489), median (IQR) viral load was 4.59 logs (4.10-5.14); the percentage of samples with viral load $\geq 5$ logs was 28.7\%. Median (IQR) time since diagnosis was 1.5 years (0.5-2.1); however, 69\% of study participants were diagnosed within 6 months prior to study entry. We were not able to determine the proportion of acute infections, but according to epidemiological data from surveillance in people starting ART in Argentina [17], this wouldn't account for more than 3\%.

Distribution of viral subtypes was: $37 \%$ subtype B; $57 \%$ BF intersubtype recombinants; $4 \%$ subtype C; and 2\% subtype F.

The prevalence $(95 \% \mathrm{Cl})$ of resistance to any antiretroviral was 16\% (11-20). Prevalence $(95 \% \mathrm{Cl})$ of resistance to NNRTIs was $13 \%(9-17)$. When analyzed by viral load subgroup (<5 logs versus $\geq 5$ logs), prevalence ( $\mathrm{Cl} 95 \%)$ of resistance mutations was 14 (9-20) versus 19 (10-31), respectively; $p=.3$ (NS).

Regarding resistance to rilpivirine, 19/239 samples were classified as harboring resistance to this antiretroviral, translating into a prevalence $(95 \% \mathrm{Cl})$ of $8 \%(5-11)$. Fifty-eight percent of the samples with resistance to rilpivirine $(n=11)$ were classified as having low-level resistance; $37 \%(n=7)$ were classified as having high-level resistance, and $5 \%(n=1)$ as with intermediate resistance. The most common mutations found were 138A $(n=6)$ and 190A $(n=4)$.

The 6 samples that harbored the 138A mutation had no other mutation associated to resistance to rilpivirine (singletons); the rest of the samples with resistance to this drug had a combination of mutations conferring cross-resistance to other NNRTIs (and none harbored the 138A mutation). (Table 3)

Prevalence $(95 \% \mathrm{Cl})$ of rilpivirine resistance was similar between the 2 most common subtypes: $8.0 \%$ (3-12) for subtype B and 7.4\% (3-13) for subtype B/F; $p=0.87$.

Prevalence of $138 \mathrm{~A}$ polymorphic mutation according to viral subtype was: $4.6 \%$ for subtype $B$ and $0.7 \%$ for subtype $B / F(p=0.059) ; 10 \%$ for subtype $C$.

According to viral load subgroup (<5 logs versus $\geq 5$ logs), prevalence ( $\mathrm{Cl} 95 \%$ ) of rilpivirine resistance was 8 (4-13) versus 9 (4-20), respectively; $p=.7$ (NS).

Prevalence $(95 \% \mathrm{Cl})$ of resistance to etravirine was $4 \%(2-7)$. 


\section{DISCUSSION}

The level of resistance to rilpivirine in people starting ARV in Argentina with no prior exposure to antiretroviral drugs is concerning. As has been mentioned, the reported prevalence of pretreatment resistance to rilpivirine is around 1\%, although a higher prevalence has been described in some countries [8-11], or regions such as Latin America and the Caribbean [7]. A previous report from our country regarding resistance to rilpivirine in HIV-positive pregnant women informed an overall prevalence of $14.3 \%$ (18.3\% for ART-experienced patients and $9.6 \%$ for naïve women), being the E138A the most frequent mutation (4.5\%) [18].

The majority of the published literature report that a very high proportion of rilpivirine associated resistance is due to the presence of mutation 138A. 138A mutation is a polymorphic substitution associated with low-level resistance to rilpivirine. It has been described as the most frequent mutation conferring resistance to this antiretroviral in many cohorts (prevalence can reach up to $5 \%)$, either for $B$ as for non-B subtypes $[11,19]$. According to our findings, the prevalence of this polymorphism in Argentina is around 2.5\%. This matches the figures already published for our region [8]. Of note, in our cohort, the majority of people without prior exposure to ART and resistance to rilpivirine do not harbor this mutation: prevalence of resistance to rilpivirine and no $138 \mathrm{~A}$ mutation is $5.4 \%$. This means that $68 \%$ of the samples with RAMs to rilpivirine do not show the 138A polymorphism in our cohort, but harbor a combination of NNRTI-associated mutations that confer resistance to this drug. This finding contrasts to the majority of previously published reports, in which the prevalence of RAMs to rilpivirine other than $138 \mathrm{~A} / \mathrm{G} / \mathrm{K} / \mathrm{Q} / \mathrm{R}$ is very low [7-11]. Regarding viral subtypes, a higher prevalence of the 138A polymorphism is described for non-B subtypes, especially in subtypes $C$ and $F$. We found that the prevalence of 138A mutation was higher in those patients infected with the B subtype than in those with HIV subtype B/F infection. Prevalence of 138A was highest among those with subtype $\mathrm{C}$ viruses, but this was infrequent in our cohort.

The level of resistance found is surprising, but is not unlikely since Argentina has a long history of ART delivery, available to all HIV-infected patients since 1992, and NNRTI-based regimens have been the preferred first-line ART regimens since more than 10 years ago. Nevirapine, which can produce mutations that confer with cross-resistance to rilpivirine, has been widely used, and there are still a considerable proportion of patients using it [20]. We believe that cross-resistance with nevirapine (and to a lesser extent with efavirenz) present in people transmitting viruses might be the most important factor driving this moderate prevalence of pre-treatment resistance to rilpivirine.

Regarding etravirine, we found a relatively low prevalence of pretreatment resistance to etravirine; lower than previously described by a study in pregnant women in Buenos Aires, Argentina [21].

The results of our study highlight the importance of performing a resistance testing before ART initiation in Argentina, even if the selected regimen contains a second generation NNRTI. 


\section{AKNOWLEDGMENTS}

The authors are thankful to Lilia Mammana and Inés Zapiola for their contribution to this study; and to Mauricio Carobene from INBIRS for his expertise and contribution on HIV-1 subtyping tools interpretation.

\section{FUNDING}

The primary survey was funded by the Ministry of Health, Argentina; and partly by the Pan American Health Organization (PAHO). This secondary analysis had no external funding.

\section{CONFLICTS OF INTEREST}

None to declare

Part of this work has been accepted for presentation as poster in the 2016 HIV Drug Therapy Conference, Glasgow. Abstract number: P357

\section{REFERENCES}

1. Ávila-Ríos S, García-Morales C, Matías-Florentino M, et al. Pretreatment HIV-drug resistance in Mexico and its impact on the effectiveness of first-line antiretroviral therapy: a nationally representative 2015 WHO survey. Lancet HIV. 2016. pii: S2352-3018(16)30119-9.

2. Bissio E, Barbás MG, Bouzas MB, et al. Pretreatment HIV-1 drug resistance in Argentina: results from a surveillance study performed according to WHO-proposed new methodology in 201415. J Antimicrob Chemother 2017; 72:504-510.

3. Chung MH, Silverman R, Beck IA, et al. Increasing HIV-1 pretreatment drug resistance among antiretroviral-naïve adults initiating treatment between 2006 and 2014 in Nairobi, Kenya. AIDS 2016; 30:1680-1682.

4. Teeranaipong P, Sirivichayakul S, Mekprasan S, et al. Role of Rilpivirine and Etravirine in Efavirenz and Nevirapine-Based Regimens Failure in a Resource-Limited Country: A Cross-Sectional Study. PLoS One 2016; 11:e0154221.

5. Benetucci J, Bissio E, Bologna R, et al. Guía para el manejo de los pacientes adultos con infección por VIH. Dirección de Sida y ETS, Ministerio de Salud de la Nación Argentina. Available at: http://www.msal.gob.ar/sida/index.php/equipos-de-salud/guias-y-recomendaciones\#nueve

6. Argentina de Infectología S. Consenso Argentino De Terapia Antirretroviral 2016/2017 (versión 2.0.2). Available at: http://sadi.org.ar/publicaciones-de-las-comisiones/item/400-consensoargentino-de-terapia-antirretroviral-2016-version-2-0-1

7. Calvez V, Marcelin AG, Vingerhoets J, et al. Systematic review to determine the prevalence of transmitted drug resistance mutations to rilpivirine in HIV-infected treatment-naive persons. Antivir Ther 2016; 21:405-412.

8. Theys K, Van Laethem K, Gomes P, et al. Sub-Epidemics Explain Localized High Prevalence of Reduced Susceptibility to Rilpivirine in Treatment-Naive HIV-1 Infected Patients: Subtype and Geographic Compartmentalization of Baseline Resistance Mutations. AIDS Res Hum Retroviruses 2016; 32:427-433.

9. Rossotti R, Fonte L, Meini G, et al. Rilpivirine resistance and the dangerous liaisons with substitutions at position 184 among patients infected with HIV-1: analysis from a national drugresistance database (ARCA). J Med Virol 2014; 86:1459-1466.

10. Alvarez M, Monge S, Chueca N, et al. Cohorte de la Red de Investigación en Sida. Transmitted drug resistance to rilpivirine in newly diagnosed antiretroviral naive adults. Clin Microbiol Infect 2015; 21:104.e1-104.e5.

11. Lambert-Niclot S, Charpentier C, Storto A, et al. Prevalence of pre-existing resistanceassociated mutations to rilpivirine, emtricitabine and tenofovir in antiretroviral-naive patients infected with B and non-B subtype HIV-1 viruses. J Antimicrob Chemother 2013; 68:1237-1242. 
Publication: Antiviral Therapy; Type: Short communication

DOI: $10.3851 / \mathrm{IMP} 3147$

12. Surveillance of HIV drug resistance in adults initiating antiretroviral therapy (pre-treatment HIV drug resistance). Concept note. World Health Organization, Geneva, Switzerland. Published March 2014. Available at: http://www.who.int/hiv/pub/drugresistance/pretreatment_drugresistance/en/

13. Wensing AM, Calvez V, Günthard HF, et al. 2015 Update of the Drug Resistance Mutations in HIV-1. Top Antivir Med 2015; 23:132-141.

14. HIVdb Program Genotypic Resistance Interpretation Algorithm Version 7.0 (last updated 02/27/14). Available at: http://sierra2.stanford.edu/sierra/servlet/JSierra

15. Bertagnolio S, Derdelinckx I, Parker M, et al. World Health Organization/HIVResNet Drug Resistance Laboratory Strategy. Antivir Ther 2008; 13 Suppl 2:49-57.

16. ACTG Laboratory Technologist Committee. ACTG Lab Man Bayer HIV-1 TRUGENE Genotyping Method, Revised Version 2.0 May 21, 2004. Available at:

https://www.hanc.info/labs/labresources/procedures/ACTGIMPAACT\%20Lab\%20Manual/Bayer\%20T ruGene\%20HIV-1\%20Genotyping.pdf

17. Boletín sobre VIH-Sida en Argentina, número 33, 2016. Dirección de Sida y ETS, Ministerio de Salud de la Nación Argentina. Available at:

http://www.msal.gob.ar/sida/index.php/publicaciones/boletines-sobre-vih-sida

18. Cecchini DM, Zapiola I, Rodriguez CG, et al. Rilpivirine resistance associated mutations in HIV-1 infected pregnant women. Enferm Infecc Microbiol Clin 2015; 33:498-499.

19. Sluis-Cremer N, Jordan MR, Huber K, et al. E138A in HIV-1 reverse transcriptase is more common in subtype $\mathrm{C}$ than $\mathrm{B}$ : implications for rilpivirine use in resource-limited settings. Antiviral Res 2014; 107:31-34.

20. Bissio E. Análisis de la utilización de fármacos antirretrovirales en Argentina. Organización Panamericana de la Salud. Available at:

http://publicaciones.ops.org.ar/publicaciones/otras\%20pub/UtilizacionRetroviralesArg.pdf

21. Cecchini DM, Zapiola I, Fernandez Giuliano S, et al. Etravirine resistance mutations in HIVinfected pregnant women. HIV Med 2013; 14:125-126.

Table 1: Baseline characteristics of all included participants $(n=270)$

\begin{tabular}{|l|l|l|}
\hline \multirow{3}{*}{ Gender (n, \%) } & Male & $180(66.7 \%)$ \\
\cline { 2 - 3 } & Female & $88(32.6 \%)$ \\
\cline { 2 - 3 } & Transgender & $2(0.7 \%)$ \\
\hline Mean( \pm SD) age, years & 36.7 years $( \pm 10.9)$ \\
\hline Median (IQR) CD4, cells/mm3 & $284 / \mathrm{mm3}(112-489)$ \\
\hline Median (IQR) viral load, logs & $4.59(4.10-5.14)$ \\
\hline Samples with viral load $\geq 5$ logs (\%) & $28.7 \%$ \\
\hline \multicolumn{2}{|c|}{ Time since HIV diagnosis (median, IQR) } & 1.5 years $(0.5-2.1)$ \\
\hline \multirow{2}{*}{$\begin{array}{l}\text { Antiretroviral regimen } \\
\text { prescribed to start }\end{array}$} & NNRTI based & $189(70 \%)$ \\
\cline { 2 - 3 } & PI based & $76(28 \%)$ \\
\cline { 2 - 3 } & INSTI based & $5(2 \%)$ \\
\hline
\end{tabular}

Table 2: Prevalence of HIV drug resistance

\begin{tabular}{|l|l|}
\hline & $\mathrm{N}, \%$ \\
\hline Total number of samples & 270 \\
\hline Samples successfully sequenced & 239 \\
\hline HIVDR prevalence $(95 \% \mathrm{Cl})$ & $37 / 239$ \\
& $16 \%(11-20)$ \\
\hline NNRTI resistance prevalence $(95 \% \mathrm{Cl})$ & $30 / 239$ \\
& $13 \%(9-17)$ \\
\hline RILPIVIRINE resistance prevalence $(95 \% \mathrm{Cl})$ & $19 / 239$ \\
& $8 \%(5-11)$ \\
\hline ETRAVIRINE resistance prevalence $(95 \% \mathrm{Cl})$ & $10 / 239$ \\
& $4 \%(2-7)$ \\
\hline
\end{tabular}


Publication: Antiviral Therapy; Type: Short communication DOI: $10.3851 / \mathrm{IMP} 3147$

Table 3: Characteristics of the samples with resistance to RILPIVIRINE and ETRAVIRINE

\begin{tabular}{|c|c|c|c|c|c|c|c|c|}
\hline $\begin{array}{l}\text { SAMPLE } \\
\text { CODE }\end{array}$ & MUTATIONS & $\begin{array}{c}\text { RESIS- } \\
\text { TANCE } \\
\text { TO } \\
\text { NVP- } \\
\text { EFV? }\end{array}$ & $\begin{array}{c}\text { RESI } \\
\text { S- } \\
\text { TANC } \\
\text { E TO } \\
\text { RPV? }\end{array}$ & $\begin{array}{l}\text { RESI } \\
\text { S- } \\
\text { TANC } \\
\text { E TO } \\
\text { ETR? }\end{array}$ & $\begin{array}{l}\text { GEN } \\
\text { DER }\end{array}$ & $\begin{array}{l}\text { AGE } \\
\text { (year } \\
\text { s) }\end{array}$ & $\begin{array}{l}\text { VIRA } \\
\text { L } \\
\text { SUB- } \\
\text { TYPE }\end{array}$ & $\begin{array}{l}\text { VIRAL } \\
\text { LOAD } \\
\text { (Logs) }\end{array}$ \\
\hline $\begin{array}{l}H R C- \\
0011\end{array}$ & $E 138 A$ & - & $R P V$ & - & $M$ & 24 & B & 4.19 \\
\hline $\begin{array}{l}H R C- \\
0012 \\
\end{array}$ & $E 138 A$ & - & $R P V$ & - & $M$ & 23 & B & 4.59 \\
\hline $\begin{array}{l}M M C- \\
0005 \\
\end{array}$ & $E 138 A$ & - & $R P V$ & - & $M$ & 39 & C & 5.70 \\
\hline $\begin{array}{l}\text { HFR- } \\
0008\end{array}$ & $E 138 A$ & - & $R P V$ & - & $M$ & 43 & F-B & $N D$ \\
\hline $\begin{array}{l}\text { HFR- } \\
0013\end{array}$ & $E 138 A$ & - & $R P V$ & - & $M$ & 56 & B & $N D$ \\
\hline $\begin{array}{l}\text { HQR- } \\
0005\end{array}$ & $E 138 A$ & - & $R P V$ & - & $M$ & 28 & $\mathrm{~B}$ & 4.26 \\
\hline $\begin{array}{l}\text { HRC- } \\
0005\end{array}$ & A98G & NVP & $R P V$ & - & $M$ & 29 & F-B & 5.53 \\
\hline $\begin{array}{l}\text { HMC- } \\
0002\end{array}$ & V106I-V179D & $\begin{array}{l}\text { NVP- } \\
\text { EFV }\end{array}$ & $R P V$ & - & $\mathrm{F}$ & 34 & B & 5.44 \\
\hline $\begin{array}{l}\text { HMB- } \\
0015\end{array}$ & V106A-V179D-P225H & $\begin{array}{l}\text { NVP- } \\
\text { EFV }\end{array}$ & $R P V$ & - & M & 58 & F-B & 4.97 \\
\hline $\begin{array}{l}\text { CST- } \\
0002\end{array}$ & K103S-Y188L & $\begin{array}{l}\text { NVP- } \\
\text { EFV }\end{array}$ & $R P V$ & ETR & M & 36 & F-B & $N D$ \\
\hline JAF-0026 & K101E - E138K & $\begin{array}{l}\text { NVP- } \\
\text { EFV }\end{array}$ & $R P V$ & ETR & $\mathrm{F}$ & 52 & $\mathrm{~F}$ & 3.64 \\
\hline $\begin{array}{l}\text { HAB- } \\
0019\end{array}$ & V179D- G190A & $\begin{array}{l}\text { NVP- } \\
\text { EFV }\end{array}$ & $R P V$ & ETR & $\mathrm{F}$ & 53 & F-B & 4.43 \\
\hline $\begin{array}{l}\mathrm{HMU}- \\
0009\end{array}$ & K101E - E138K & $\begin{array}{l}\text { NVP- } \\
\text { EFV }\end{array}$ & $R P V$ & ETR & M & 29 & F-B & 5.38 \\
\hline $\begin{array}{l}\mathrm{HMU}- \\
0014\end{array}$ & K103N-Y181C & $\begin{array}{l}\text { NVP- } \\
\text { EFV }\end{array}$ & $R P V$ & ETR & $\mathrm{F}$ & 48 & F-B & 3.39 \\
\hline $\begin{array}{l}\text { HQR- } \\
0003 \\
\end{array}$ & K101E-G190A & $\begin{array}{l}\text { NVP- } \\
\text { EFV }\end{array}$ & $R P V$ & ETR & M & 38 & $\mathrm{~B}$ & 3.69 \\
\hline $\begin{array}{l}\text { HRM- } \\
0010 \\
\end{array}$ & $\begin{array}{c}\text { K101E-E138K-V179T- } \\
\text { Y181C-G190S }\end{array}$ & $\begin{array}{l}\text { NVP- } \\
\text { EFV }\end{array}$ & $R P V$ & ETR & M & 37 & F-B & 3.72 \\
\hline $\begin{array}{l}\text { HPR- } \\
0003 \\
\end{array}$ & A98G- G190A & $\begin{array}{l}\text { NVP- } \\
\text { EFV }\end{array}$ & $R P V$ & ETR & $\mathrm{F}$ & 23 & B & 3.68 \\
\hline $\begin{array}{l}\mathrm{HAL}- \\
0011\end{array}$ & $\begin{array}{c}\text { K101E-Y181C-G190A- } \\
\text { P225H }\end{array}$ & $\begin{array}{l}\text { NVP- } \\
\text { EFV }\end{array}$ & $R P V$ & ETR & $\mathrm{F}$ & 23 & $\mathrm{~B}$ & $N D$ \\
\hline $\begin{array}{l}\text { HMB- } \\
0001\end{array}$ & V106I-V179D-Y188L & $\begin{array}{l}\text { NVP- } \\
\text { EFV }\end{array}$ & $R P V$ & ETR & $\mathrm{F}$ & 22 & B & 4.25 \\
\hline
\end{tabular}

